\title{
periferio
}

\section{PARA DISCUTIR (AINDA MAIS) GÊNERO E SEXUALIDADE NA ESCOLA: POLÍTICAS E PRÁTICAS DE RESISTÊNCIAS}

\author{
Ivan Amaro ${ }^{1}$ \\ Universidade do Estado do Rio de Janeiro - UERJ
}

Os últimos meses têm sido bastante sombrios em termos de retrocessos de nossos direitos e de fortes ataques à democracia. 0 país parece ter entrado num verdadeiro estado de exceção, paradigma de governo que tem se tornado dominante no jogo político contemporâneo e que se apresenta como um espaço de indeterminação entre democracia e absolutismo. Para Agamben (2004, p. 12), “as medidas excepcionais encontram-se na situação paradoxal de medidas jurídicas que não podem ser compreendidas no plano do direito, e o estado de exceção apresenta-se como a forma legal daquilo que não pode ter forma legal".

As medidas que têm sido encaminhadas no Congresso Nacional desde abril de 2016 parecem contribuir para este desenho de exceção: retirada de direitos trabalhistas, redução de investimentos em programas sociais, redução programas que protegem das populações indígenas, quilombolas, negros e negras, comunidade LGBTTTIQ (Lésbicas, Gays, Bissexuais, Travestis, Transexuais, Transgêneros, Intersexuais e Queer). Em junho de 2016, a ABGLT (Associação Brasileira de Lésbicas, Gays, Bissexuais, Travestis e Transexuais) denunciou as ameaças de retrocesso dos direitos humanos, no Conselho de Direitos Humanos da ONU (Organização das Nações Unidas).

Nesse sentido, os diversos movimentos nos campos do executivo, do legislativo e judiciário corroboram para um alarmante desmanche de direitos sociais e de ataques e violências diversas desferidas contra categorias inteiras de cidadãos - funcionários/as públicos/as, quilombolas, indígenas, negros/as,

\footnotetext{
1 Pós-Doutor em Educação (UFF), Doutor em Educação (Unicamp), Professor do quadro permanente do Programa de Pós-Graduação em Educação, Cultura e Comunicação em Periferias Urbanas (FEBF/UERJ). ivanamaro.uerj@gmail.com.
} 


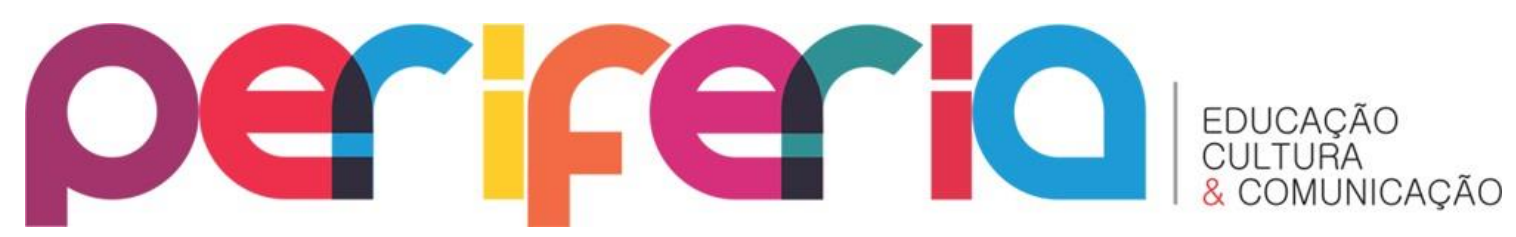

mulheres, gays, transexuais, trabalhadores/as. No Brasil, o quadro de violência é marcadamente definido pelos cruzamentos entre gênero, raça e classe. Como afirma Butler (2015), nossas vidas se interconectam, são interdependentes e nos levam a questionar: que vidas importam? Tais ataques, interdições, censura e regulação ao caráter democrático da sociedade brasileira atinge, também, o espaço da escola, seus sujeitos, suas práticas, seus currículos, suas finalidades. Esta situação impõe a nós, educadores/as, pesquisadores/as assumirmos a resistência e a defesa da produção de conhecimentos que se contraponham aos discursos do senso comum ou enviesados política e teoricamente.

A violência é algo abominável para todas as pessoas, e em qualquer sociedade. Porém, parece estar naturalizada a ideia de a violência sofrida por alguns grupos sociais é aceitável. Os discursos constituídos colocam como normal, por exemplo, um homem violentar uma mulher porque ela estava "se oferecendo ao usar roupas sensuais". Há uma lógica do "estupro corretivo" como forma de “ensinar" lésbicas a serem “mulheres”. Há uma outra lógica naturalizada de que gays, transexuais e travestis devem apanhar na rua para aprenderem a "ser homens". Nesse sentido, a violência é aclamada quando serve para reiterar normas inteligíveis ou reafirmar a supremacia masculina sexista e heterossexual. Para Foucault (1994), todo o processo de discursificação do sexo não tem a intenção de produzir maior liberdade, pelo contrário, busca constituir uma aparelhagem para produzir discursos sobre sexo para produzirem efeitos sobre a economia, ou seja, tornar os discursos sobre sexo como racionalidade. Isso implica em criar todo um arcabouço de interesse público para regular nossas vidas. Conforme Foucault (1994),

[...] deve-se falar dele como de uma coisa que não se tem simplesmente que condenar ou tolerar, mas que gerir, que inserir em sistemas de utilidade, que regular para o bem de todos, que fazer funcionar em ordem a um óptimo. 0 sexo não se julga apenas, administra-se. Ele tem que ver com o poder público; exige processos de gestão; deve ser objeto de discursos analíticos. (FOUCAULT, 1994, p. 28) 


\section{periferio}

Dentro dessa visão, as políticas públicas tornam-se instrumentos fortes do poder de controle, de silenciamentos, de censura. Estas políticas, sediadas a partir dos discursos da legalidade jurídica, definem quem merece e quem não merece atenção do estado. Quem merece e quem não merece o benefício do direito. Assim, percebemos que há uma norma presente que define as vidas que merecem solidariedade humana e as que não merecem tal tratamento. Uma vida só pode ser considerada como tal quando corresponde aos padrões produzidos e regulados socialmente: não há como existir uma vida se ela não se submeter aos enquadramentos.

A inteligibilidade ${ }^{2}$ se faz presente e toda 'vida' que transcende esta norma se torna mais vulnerável à violência. Vidas que estão para além do padrão cisgênero ${ }^{3}$, heterossexual, quando são perdidas, muitas vezes, não são lamentadas pois não possuíam o status de vida. Um corpo sempre está entregue a vulnerabilidade do outro. Um corpo está sempre exposto a enquadramentos que determinam vidas que podemos ou não chorar. Butler (2015, p. 17) denomina como precarização da vida: “O 'ser' da vida é ele mesmo constituído por meios seletivos; como resultado, não podemos fazer referência a esse "ser" fora das operações de poder e devemos tornar mais precisos os mecanismos específicos de poder mediante os quais a vida é produzida. (BUTLER, 2015, p.17)

A retirada de qualquer menção aos termos gênero, sexualidade e orientação sexual nos planos de educação reforça a ideia de interdição, de censura, de silenciamento por meio das regulações jurídicas e políticas . 0 movimento de diversas casas legislativas municipais e estaduais para aprovar

\footnotetext{
2 Trata-se de um conceito em que os gêneros são coerentes quando estão de acordo com a norma do sexo: alguém que nasce com pênis, será homem, deve performatizar signos ditos masculinos. Alguém que nasce com vagina, será mulher e deve performatizar os signos considerados femininos. A inteligibilidade é um conceito que trabalha os gêneros como binários em que estão calcados numa matriz heteronormativa.

${ }^{3} 0$ terno cisgênero se refere às pessoas cujo gênero é o mesmo que o designado em seu nascimento.
} 


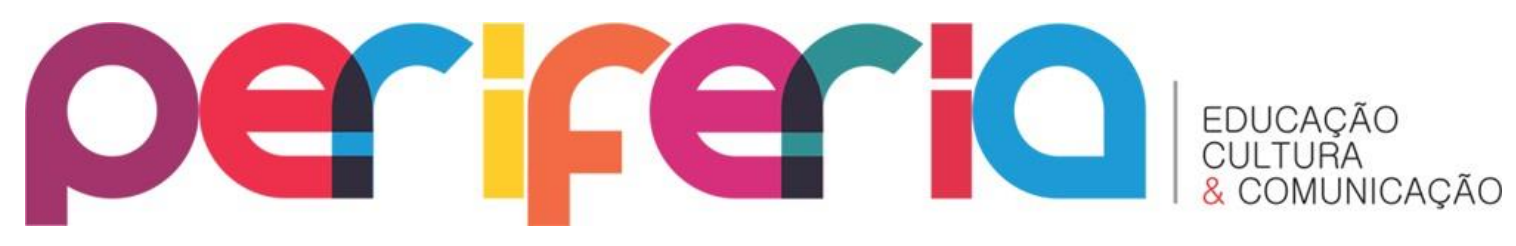

leis que proíbam a difusão e/ou divulgação de qualquer material alusivo às discussões de gênero na escola contribui para este quadro de retrocesso. $\mathrm{Na}$ prática, parece mesmo um retorno ao Século XVII em que, conforme Foucault (1994), após um momento de certa liberdade para lidar com as sexualidades, sem censura, sem interdições, segue-se um período sombrio. Dessa forma, “ a sexualidade é aferrolhada. Transfere-se. A família conjugal confisca-a e absorve-a inteiramente na seriedade da função de reproduzir. Em torno do sexo, faz-se silêncio" (FOUCAULT, 1994, p. 09).

E é na direção de construirmos uma reação a esta nova etapa de crepúsculos, sombras e obscurantismos que tentam nos impor que organizamos este dossiê: "Gênero, sexualidades e educação: políticas e práticas". Os artigos aqui inseridos apresentam uma discussão de fundo bastante relevante para o momento atual: desconcertar discursos, afrontar e explicitar violências e, por fim, apontar caminhos de resistência.

0 artigo "Prática conservadoras: suas influências nas tessituras identitárias de gêneros e sexualidades", de Denize Sepulveda e José Antonio Sepulveda, abre este dossiê pautando-se na discussão sobre os efeitos do conservadorismo que se manifesta como um movimento de interdições e censura às sexualidades e aos comportamentos de gêneros. A partir da análise de um caso de um alunx de uma escola pública do Estado do Rio de Janeiro, os autores traçam os efeitos que o pensamento conservador imprime sobre as identidades de gênero e sexuais de pessoas que não se encontram dentro da norma heterossexual. Foram realizadas entrevistas e utilizado como referencial o paradigma indiciário a fim de encontrar pistas, indícios e sinais de práticas conservadoras nas escolas. A partir dos achados, aponta-se para a necessidade de constituir lutas contra práticas conservadoras a partir de alternativas mais democráticas e pautada no respeito. Nesse sentido, é preciso pensar em alternativas que proporcionem o direito à formação da identidade pessoal que não se encaixe em modelos heteronormativos. É preciso continuar lutando contra as exclusões de diversas ordens que são princípios do pensamento conservador. 


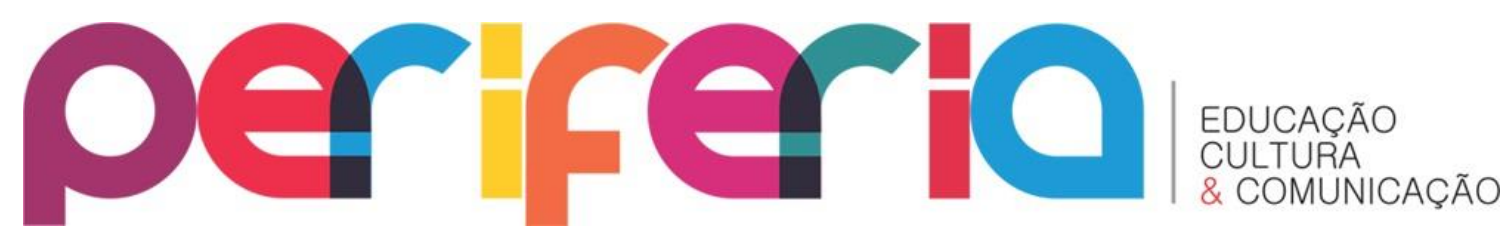

A partir de experiências docentes narradas por meio de pesquisa autoetnográfica, Paulo Melgaço da Silva Júnior e Marcio Caetano, em seu artigo "Narrativas em primeira pessoa: experiências docentes, gênero e sexualidades", buscam questionar as práticas pedagógicas, considerando as experiências docentes de um deles como produtoras de modos de subjetivação, articulando saberes, posicionando os sujeitos e regulando os comportamentos na escola. Os autores compreendem que as identidades são produzidas e marcadas pela cultura e, portanto, reconhecem a possibilidade de reinvenção do sujeito nos jogos interpelativos das regulações sexuais. Com a narração de duas experiências vivenciadas em duas escolas públicas dos municípios fluminenses de Guapimirim e São Gonçalo, os autores colocam em tensão as diversas conformações de masculinidades e feminilidades. Neste sentido, afirmam que os corpos sexuados são construídos e historicamente naturalizados como diferentes e que compõem o espectro da disputa de saberes que se instaurou na e com a escola. O gênero é constituído socioculturalmente e sua inteligibilidade dissemina-se por tecnologias educativas diversas. Consideram que o gênero é constituído a partir das leituras feitas dessas tecnologias e das performances que nos regulam. Apontam que aqui pode indicar uma encruzilhada em que o (s) ponto (s) de fratura e resistência aos movimentos de normalização e normatização sexual possam emergir. Por fim, afirmam que as sexualidades e o gênero assumem configurações fluidas, instáveis, inacabadas. As experiências vividas descrevem, por um lado, o quadro produtivo de identidades e sugeremi que as interações cotidianas têm o poder de criar e tornar as nomeações em "senso comum". Por outro lado, há indicações de que há um esforço quase ativista de diversos sujeitos em contrariar as heterodesignações hegemônicas sobre as sexualidades e as performatividades de gêneros marginais.

Em "Aí que acaba meu mar de rosas e começa o meu calvário: gênero, sexualidade e o aprendizado com a diferença", Dilton Ribeiro do Couto Júnior apresenta achados de pesquisa que buscou investigar as marcas de abjeção de um grupo de jovens no Facebook. 0 grupo constituiu-se por jovens que se 


\section{periferio}

autoidentificavam como lésbicas e bissexuais. As discussões desse grupo se posicionavam claramente com um crítica à heteronormatividade. 0 autor busca fazer uma reflexão situando a educação dentro de um espectro da diferença, analisando um relato de um dos membros do grupo. 0 relato foi analisado tomando como suporte autores referenciados nas concepções de relações de poder, heteronormatividade, diferença, produção de estereótipos e representações. A perspectiva queer é tomada, também, como teoria que contribui para desnaturalizar e ressignificar a matriz hegemônica da heterossexualidade. Como parte dos achados, o autor aponta para reafirmar que o cotidiano escolar é perpassado pela sexualidade e estimular o interesse de jovens, mas que é simplesmente ignorado pelas práticas pedagógicas. No entanto, mesmo que a temática seja 'escondida' na sala de aula, discursos e práticas de professores e professoras conformam a visão heteronormativa como padrão. Aponta como proposição que pensemos numa educação com a diferença reconhecendo a necessidade de transformar, em "mares de rosas", o "Calvário" de muitos sujeitos nos seus enfrentamentos cotidianos.

No artigo seguinte, "Declarações de amor gay no colégio: os comentários de uma postagem no Facebook", Luciano Pereira dos Santos também localiza sua pesquisa no espaço do Facebook, compreendendo as redes sociais como lugares de encontro, de trocas, de exposição de si. Seu texto tem como objetivo a discussão das percepções relativas às homossexualidades a partir de uma análise dos comentários gerados por uma postagem de um vídeo gravado pela ocasião do pedido de namoro feito por um adolescente a outro, no pátio da escola em que estudam e que foi compartilhado publicamente no Facebook. 0 vídeo suscitou diversos comentários, tanto favoráveis como contrários. O autor categorizou os comentários nos seguintes eixos: apoio, repúdio e indefinidos/marcação de amigos. Grande maioria postou comentários de apoio, compondo um universo de $61 \%$. Comentários de repúdio configuraram um total de $25 \%$ e os demais foram enquadrados na categoria 'indefinidos/marcação de amigos, ou seja, aqueles e aquelas que não expuseram os comentários. 0 autor conclui que as 


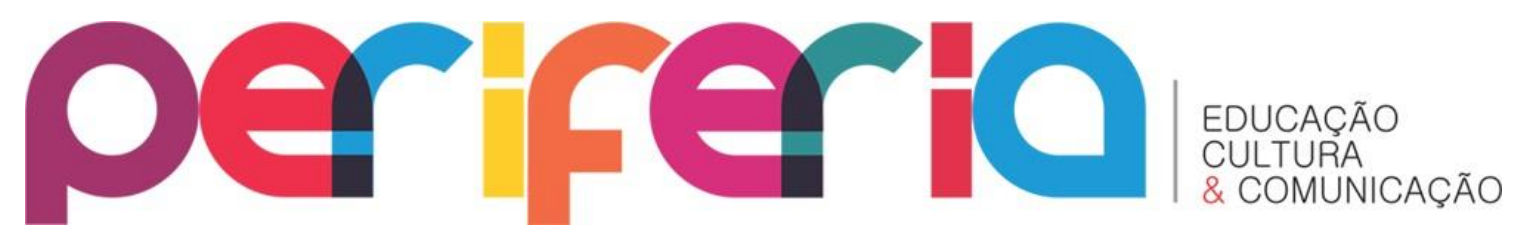

discussões sobre gênero e sexualidade tem mobilizado diferentes opiniões e movimentos no interior da escola. Neste sentido, considerada uma temática que provoca embates, disputas, repressões, observa-se, por outro lado que há resistências e mobilizações contra a homofobia e de apoio aos que não se enquadram em padrões heternormativos, indicando grande potência para intensificar a discussão no espaço escolar.

Leonardo Nolasco Silva e Bruno Rossato, no artigo “Audiovisualidades e produção social das masculinidades: gêneros-corpos-sexualidades encenadas nos cotidianos das salas de aula", defendem a potência das audiovisualidades como dispositivos pedagógicos no dentrofora das salas de aula. Os autores compreendem que a formação se dá em redes de significação e subjetividades que não se reduzem apenas à experiência escolar/acadêmica. Sustentando-se num dos aportes do cotidiano, discutem como os personagens-heróis de desenhos animados e de uma série de TV são apropriados pelos praticantes nas salas de aula. O audiovisual é concebido como tecnologia social que participa da produção simbólica dos corpos e dos comportamentos. A partir dessas percepções, as narrativas, disparadoras de subjetivação, servirão de linha para as costuras teóricas sobre a construção social das masculinidades. Para as análises, levantam questões: de que modo as encenações do masculino presentes nos desenhos animados atravessam os estudantes e potencializam discursos sobre as masculinidades? Que pistas o consumo destes audiovisuais oferecem para pensarmos juntos as (des) construções de gênero nos cotidianos da escola e da universidade? Como esses disparadores e as conversas tecidas a partir deles nos ajudam a pensar o currículo? No processo de discussão das narrativas, os autores percebem pistas que confrontam os modos diversos de apropriação que os praticantes fazem dos super-heróis. As crianças provocam e abalam as estruturas de tal forma que não somente a coloca numa posição de ruptura diante do adulto com a transforma na tradutora. Para os autores, "vestimos masculinidades nem sempre confortáveis e esquecemos (tantas vezes!) que a prática dispensa manual de instruções e que ser homem é da ordem da invenção." 


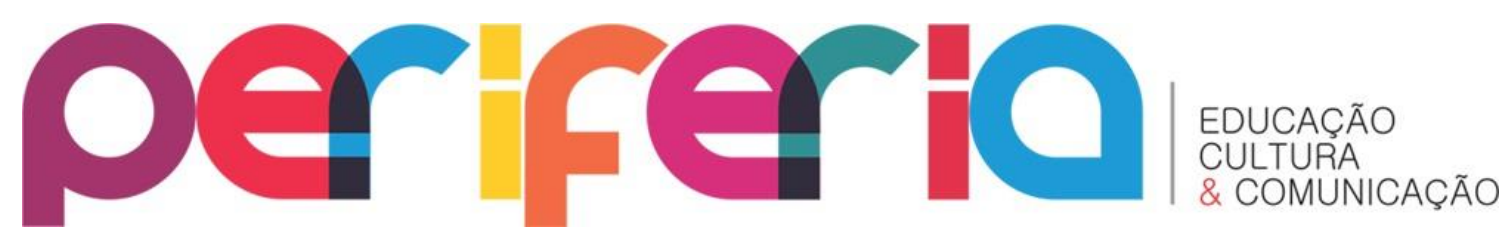

Com o objetivo de promover uma discussão teórica sobre a violência de gênero articulando-a às políticas públicas como forma de seu enfrentamento, Rosane Cristina de Oliveira e Elaine Cristina Tenório Cavalcanti, no artigo intitulado "Políticas públicas de combate e enfrentamento à violência de gênero", retratam o quadro triste que atinge mulheres em todo o mundo. A violência de gênero assenta-se na tradição cultural, na organização social, nas estruturas econômicas e nas relações de poder. 0 simples fato de ser mulher é justificado como motivo para o exercício de tal violência, o que explicita as desigualdades socioculturais entre homens e mulheres e que gera um cenário de relações desiguais, de discriminação, de subordinação e de abuso de poder. Dados apontam que o violador, o agressor é, em grande parte, sujeitos próximos às mulheres. São maridos, ex-maridos, namorados, ex-namorados... A violência doméstica é considerada uma das principais causas de morte ou de incapacitação física em mulheres na faixa etária entre 15 e 44 anos. A partir de análises diversas do quadro de violência, as autoras apontam a necessidade de avançar nas pautas reivindicatórias de políticas públicas de proteção à mulher, bem como de prevenção e combate a todo e qualquer tipo de violência contra a mulher. Ao fazerem um apanhado teórico das diversas visões da violência contra a mulher e da perspectiva de enfrentamento se dar, também, via políticas públicas, as autora concluem que tais políticas são necessárias para respeitar a igualdade nas relações de gênero e consolidar a cidadania da mulher. Políticas que permitam facilitar as denúncias, que propiciem proteção e apoio à mulher vítima de violência podem contribuir para o enfrentamento da violência de forma conjunta e articulada entre diversas redes e esferas: saúde, educação, assistência social, segurança pública, justiça. É necessário que órgãos componentes da Rede de Atendimento atuem de forma articulada para garantir a integralidade da assistência à mulher.

Em "Tempo de uma nova vida e espaço de resistência: uma experiência entre gestantes e puérperas do preventório com a frente de saúde popular do MTST", Karina Caetano, relata sua trajetória na construção de sua pesquisa a 


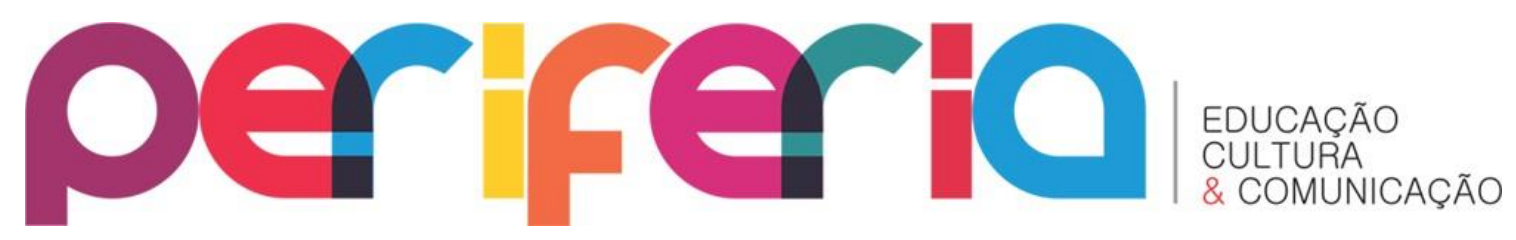

partir do seu encontro com um grupo de Mães do MTST, do Morro do Preventório, RJ, vinculado à Frente de Saúde Popular do movimento e ao Projeto de Extensão Liga Multiprofissional de Saúde de Família/UFF. As atividades articulam múltiplos sujeitos e coloca saberes populares, femininos e favelados em diálogo com conhecimentos médicos e acadêmicos. A partir da educação popular em saúde, tempo, espaço e sujeitos são (re)pensados para compreender coletivamente como as participantes entendem a si, a maternagem e seus direitos. O objetivo é analisar como as mulheres se organizam no território e como vivem o período da gestação junto desse processo educativo. As histórias são repletas de dificuldades, de enfrentamentos, de lutas, de violências, mas também de muita parceria, de muita coletividade. Ao fim, a autora percebe que é necessário compreender tempo e espaço em que os sujeitos da pesquisa e da extensão estão vinculados e que auxiliam na produção de um conhecimento coerente com sujeitos envolvidos, a melhor compreender suas lutas, bem como fazer com que os conteúdos a serem trabalhados dialoguem com seus modos de vida. As mulheres, pobres, moradoras da periferia de Niterói, mães e, em sua maioria, negras, são sabedoras dos desafios que terão para maternar suas crias em territórios onde direitos thes são negados. Articular educação e saúde populares é fundamental para constituir sujeitos que se (re) conheçam como potentes na construção de suas histórias.

Este dossiê fecha de forma "lacradora". O artigo "Bichas destruidoras mesmo: construindo uma viada bem afeminada", Anderson Cacilhas Santiago, Naiara Ferreira Vieira Castello e Alexsandro Rodrigues nos levam pelos caminhos da produção da identidade afeminada, a partir de dois vídeos e um filme documentário, publicados na internet: “Gays afeminados”, “Lázaro 22" e “Bichas, o documentário”. Ao procederem uma discussão analítica e crítica das audiovisualidades em questão, constatam que as produções são fortes no processo de contestação do lugar abjeto destinado aos gays afeminados, retomando-os como potência transformadora. A partir de um referencial queer, dos estudos culturais, feministas, pós-estruturalistas o artigo procura 


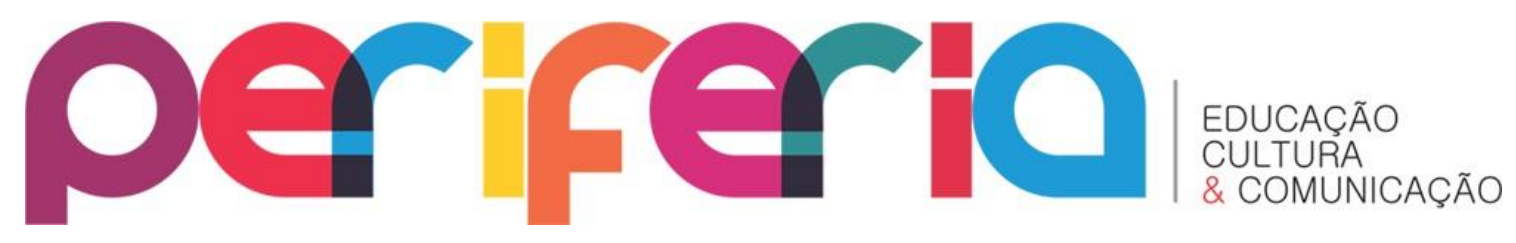

por em questão as terminologias ofensivas que são utilizadas para atribuir, principalmente, homens gays afeminados. "Bicha" é um termo tornado político e potente para o enfrentamento da homofobia. Os autores e a autora partem da ideia de que "bicha" assume este caráter político e assumem-no como termo afirmativo, potente. Afirmam que, longe de caberem nas categorizações diversas, as bichas afirmam-se na diferença - afinal, a identidade é sempre escorregadia, escapando ao seu próprio propósito de homogeneização e à estereotipização. Acredita-se que os vídeos, sobretudo a partir do momento em que extrapolam o ambiente da internet e influenciam o agendamento da grande mídia, eles acabam se tornando ferramentas de transformação do modelo de dominação masculinista, inclusive do ideal de masculinidade hegemônica e da heteronormatividade afirmados pelas próprias bichas.

Por fim, este dossiê traz ainda um conjunto de artigos e fluxo contínuo, que continua o debate sobre a educação, cultura e comunicação em periferias urbanas, fazendo interlocuções entre as mídias digitais, a formação de professores e a questão do currículo escolar, além de apontarem para uma visão histórica e contemporânea de docência. Assim, a necessidade constante de discussão sobre essas temáticas continua presente na Revista Periferia, sob variadas abordagens metodológicas e epistemológicas.

Queremos que a leitura desse dossiê seja pensada, sentida, problematizada e que funcione como propulsão aos deslocamentos e desalojamentos na perspectiva de compreendermos que políticas e práticas se confrontam e se configuram nos espaços diversos formativos. A escola é um desse espaços, mas os territórios da saúde, do cinema, dos movimentos sociais, das audiovisualidades também são necessários e relevantes para desconcertarmos padrões e mundos tão heteronormativos. Como se percebe nos vários textos aqui apresentados, gênero e sexualidades já estão em todos os lugares. Não tem volta. Por isso, precisamos (ainda mais) falar, discutir, debater estas temáticas nas mais diversas esferas sociais e culturais. 


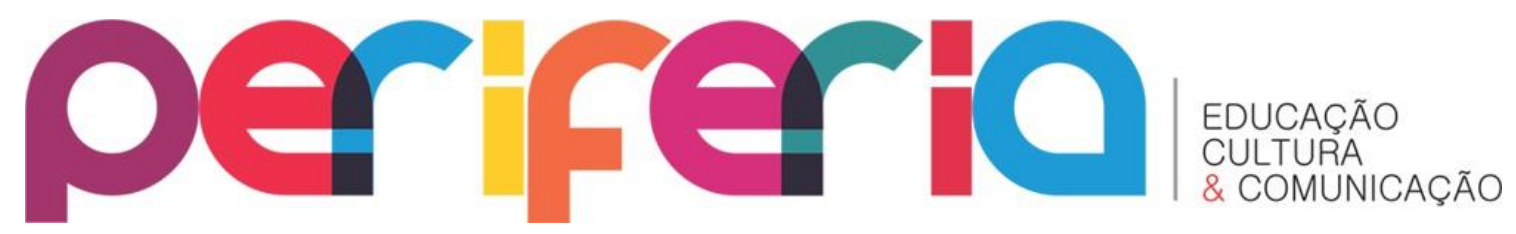

\section{REFERÊNCIAS}

AGAMBEN, G. Estado de exceção. São Paulo: Boitempo, 2004.

BUTLER, J. Quadros de guerra - Quando a vida é passível de luto? Rio de Janeiro: Editora Civilização Brasileira.2015.

FOUCAULT, M. História da Sexualidade - vontade de saber. Relógia D’Água Editores: Lisboa, 1994. 